\title{
PERGESERAN KESANTUNAN POSITIF SISWA KELAS IX MTs N 1 SURAKARTA BERLATAR BELAKANG BUDAYA JAWA
}

\author{
Khilyatin Ulin Noor dan Harun Joko Prayitno \\ Program Studi Pendidikan Bahasa Indonesia \\ Fakultas Keguruan dan Ilmu Pendidikan \\ Universitas Muhammadiyah Surakarta
}

khilyatin_ums@ymail.com

\begin{abstract}
Abstrak
Tujuan penelitian ini adalah untuk mendeskripsikan pola kesantunan dan bentuk-bentuk pergeseran kesantunan positif yang digunakan di kalangan siswa kelas IX MTs N 1 Surakarta. Selain itu, penelitian ini juga bertujuan untuk mengetahui factor-faktor yang mempengaruhi kemunculan pergeseran kesantunan positif di kalangan siswa kelas IX MTs N 1 Surakarta. Penelitian ini tergolong penelitian deskriptif kualitatif. Data penelitian berupa tuturan siswa kelas IX yang mengandung kesantunan positif. Teknik pengumpulan data adalah teknik simak catat. Sumber data adalah semua siswa kelas IX MTs N 1 Surakarta. Metode analisis mencakup metode padan intralingual dengan menghubungbandingkan unsur-unsur yang bersifat lingual serta metode padan ekstralingual dengan menghubungbandingkan unsur-unsur bahasa yang berupa bentuk itu dengan hal yang di luar bahasa. Hasil penelitian menunjukkan bahwa terdapat 6 bentuk pergeseran kesantunan positif yang kemudian mengarah pada 13 pola strategi kesantunan positif yang digunakan siswa berlatar belakang kebudayaan Jawa. Pola-pola strategi tersebut mencakup pola memperhatikan kesukaan, keinginan, dan kebutuhan lawan tutur; membesar-besarkan perhatian, persetujuan, dan simpati kepada lawan tutur; menggunakan penanda identitas kelompok; Mencari persetujuan dengan mengulang sebagian atau seluruh ujaran penutur (lawan tutur); menghindari ketidaksetujuan dengan pura-pura setuju atau persetujuan yang semu (psedo agreement), menipu untuk kebaikan (white lies), pemagaran opini (hedging opinion); Menunjukkan hal-hal yang mempunyai kesamaan melalui basa-basi (small talk) dan pranggapan (presupposition); menggunakan lelucon; menyatakan paham atau mengerti akan keinginan lawan tutur; memberikan janji; menunjukkan sikap keoptimisan; melibatkan penutur dan lawan tutur dalam aktivitas; memberikan pertanyaan atau meminta alasan; serta menyatakan hubungan secara timbal balik (resiprokal). Selain itu, ada beberapa faktor yang mempengaruhi pergeseran kesantunan positif, yaitu jarak sosial, konteks, keinginan untuk memuji yang berlebihan, sengaja meminta alasan, tidak ingin dirugikan, dan penolakan terhadap sesuatu.
\end{abstract}

Kata Kunci: Kesantunan positif, Pergeseran, Strategi, siswa kelas IX Mts N 1 Surakarta.

\begin{abstract}
This research aims to describe the pattern of politeness and the shifts of positive politeness among students of class IX MTs N 1 Surakarta. In addition, this research also aims to identify the factors that are influencing the emergence
\end{abstract}


of positive politeness shift among those students. This research is classified as descriptive qualitative research. The data includes speech of class IX's students that contains positive politeness. The data collected by taking notes from the students'speech. Data sources are all students of class IX MTs N 1 Surakarta. Methods in analysis include the intralingual match methods by comparing the lingual elements with the extra-lingual elements. The results showed that there are six forms of positive politeness shifts which then lead to the 13 patterns of positive politeness strategy used by students who have Javanese culture backgrounds. Those patterns include attention to the pattern of preferences, desires, and the needs of what opponent said; exaggerate things to get attention, approval, and sympathy from the opponents; using a marker of group identity; seeking approval to repeat some or all of the speakers utterances; pseudo agreement, white lies, hedging opinion; small talk and presuppositions; jokes; expressed understanding or understanding what are the opponent said; making promises; show an attitude of optimism; involves the opponents in the activities; ask questions or give reasons; also reciprocal relationship. In addition, there are several factors that are influencing positive politeness shifts. They are social distance, contexts, excessive complimenting, deliberately asked for a reason, no harm intentions, and rejections.

Keywords: positive politeness, shifts, strategy, students of class IX MTs N 1 Surakarta

\section{Pendahuluan}

Bahasa menunjukkan cermin pribadi seseorang. Karakter, watak, atau pribadi seseorang dapat diidentifikasi dari perkataan yang diucapkan. Penggunaan bahasa yang sopan, santun, sistematis, teratur, jelas, dan lugas mencerminkan pribadi penuturnya yang berbudi. Upaya untuk menciptakan lingkungan masyarakat yang bertutur kata santun merupakan hal yang sangat penting. Setiap perubahan masyarakat melahirkan konsekuensi-konsekuensi tertentu yang berkaitan dengan masalah nilai dan moral. Dalam kondisi ini, pendidikan di sekolahan dituntut untuk memiliki kemampuan mendidik dan mengembangkan etika berbahasa santun agar siswa dapat berkomunikasi dengan lebih baik.

Pemahaman nilai kesantunan tidak terkait dengan bakat (talent) yang diperoleh secara turun temurun, tetapi muncul sebagai bentuk kompetensi yang diperloeh dengan pemahaman terhadap aspek sosial dan psikologis yang perlu diperhatikan dalam bertutur. Nilai budaya yang tinggi tidak dibawa sejak lahir, tetapi berasal dari proses sosialisasi dan konstruksi sosial budaya suatu bangsa. Dijelaskan pula oleh Deutshmann (2003:24) bahwa kesantunan tidak bersifat universal, tetapi berlatar sosial sehingga bentuk dan latar tidak bisa dipisahkan. Ada tiga hal yang menentukan bentuk kesantunan, yaitu norma budaya, situasi, dan sifat pesan yang disampaikan. Dapat dipahami pula bahwa konteks tuturan menentukan bentuk kesantunan yang diperankan oleh penutur.

Kesantunan lebih berkenaan dengan subtansi bahasa, sedangkan etika berkenaan dengan perilaku atau tingkah laku dalam bertutur. Tingkah laku dalam berbahasa haruslah disertai norma-norma yang berlaku dalam budaya itu. Beberapa pakar menyebut norma-norma budaya tersebut sebagai etika berbahasa atau tata cara berbahasa.

Beberapa pakar yang membahas kesantunan berbahasa antara lain, Lakoff (1972), Fraser (1978), Brown dan Levinson (1978), serta Lecch (1983). Menurut Brown dan Levinson (1978) teori tentang kesantunan berbahasa itu berkisar atas nosi muka atau wajah, yakni "citra diri" yang bersifat umum dan selalu ingin dimiliki oleh setiap anggota masyarakat. Muka ini meli- 
puti dua aspek yang saling berkaitan, yaitu muka negatif dan muka positif. Muka negatif itu mengacu pada citra diri setiap orang yang berkeinginan agar ia dihargai dengan jalan membiarkannya bebas melakukan tindakannya atau membiarkannya bebas dari keharusan untuk mengerjakan sesuatu. Sementara itu, muka positif mengacu pada citra diri setiap orang yang berkeinginan agar hal yang dilakukannya dan dimilikinya atau hal yang merupakan nilai-nilai yang ia yakini diakui orang lain sebagai suatu hal yang baik, yang menyenangkan, dan yang patut dihargai. Karena ada dua sisi muka yaitu muka positif dan muka negatif, kesantunan pun dibagi menjadi dua, yaitu kesantunan negatif untuk menjaga muka negatif dan kesantunan positif untuk menjaga muka positif. Kesantunan ini dapat ditafsirkan sebagai upaya untuk menghindari konflik antara penutur dan lawan tuturnya di dalam proses komunikasi.

Pemakaian budaya santun dalam ragam kesantunan positif perlu diterapkan di kalangan generasi muda, termasuk pelajar. Tuturan yang santun merupakan alat yang paling tepat digunakan dalam berkomunikasi. Anak perlu dibina dan didik agar mampu bertutur santun positif karena anak merupakan generasi penerus yang akan hidup sesuai dengan zamannya. Bila anak dibiarkan bertutur tidak santun, tidak mustahil tuturan santun positif yang sudah ada pun bisa hilang dan selanjutnya lahir generasi yang arogan, kasar, dan kering dari nilai-nilai etika dan agama.

Meskipun demikian, kadang-kadang nilai dari kesantunan positif ini sering sekali mengalami pergeseran dari penggunaannya, hal ini disebabkan oleh beberapa faktor. Pergeseran kesantunan positif ini dapat terjadi pada kalangan pelajar terhadap gurunya. Sering dijumpai beberapa kasus pergeseran kesantunan positif di kalangan pelajar yang berlatar belakang kebudayaan Jawa, seperti pada tuturan berikut:

(1) Sari : "Wah sepatune anyar cah,.. tukune ngendi Nur?"

(Wah sepatunya baru, belinya di mana Nur?)

Nur : "Embuh Bapakku kok, lha dari pada kena razia meneh."

(Gak tahu Bapakku kok, dari pada kena razia lagi)

Konteks: Percakapan diatas terjadi ketika penutur $(\mathrm{Pn})$ tertarik melihat sepatu baru milik mitra tutur (Mt). Pn memuji sepatu baru Mt. Pn ingin tahu tempat Mt membeli sepatu baru sekaligus Pn ingin tahu alasan Mt membeli sepatu baru. Mt baru saja terkena razia kerapian karena sepatunya yang dulu melanggar peraturan.

Ujaran (1) yang disampaikan Pn terhadap Mt secara tersirat mengandung makna mengejek. Konteksnya, beberapa hari yang lalu, Mt terkena razia sepatu oleh guru olahraga yang saat itu sedang melakukan ketertiban atribut seragam. Secara tidak langsung, tuturan Pn "Wah sepatune anyar cah... tukune ngendi Nur? " mengingatkan $\mathrm{Mt}$ tentang kejadian tersebut dengan membesar-besarkan perhatiannya terhadap sepatu baru yang saat itu dikenakan oleh Mt.

Pada penelitian ini, yang menjadi rumusan masalah adalah (1) bagaimanakah pola kesantunan yang digunakan oleh kalangan siswa kelas IX MTs N 1 Surakarta dan (2) bagaimanakah bentuk-bentuk pergeseran kesantunan positif yang terjadi serta (3) faktor apa sajakah yang mempengaruhi pergeseran kesantunan positif di kalangan siswa kelas IX MTs N 1 Surakarta. Sementara itu, tujuan pada penelitian ini adalah mendeskripsikan pola kesantunan yang di- 
gunakan di kalangan siswa kelas IX MTs N 1 Surakarta, menjelaskan bentuk-bentuk pergeseran kesantunan positif yang terjadi di kalangan siswa kelas IX MTs N 1 Surakarta, serta mengetahui factor-faktor yang mempengaruhi pergeseran kesantunan positif di kalangan siswa kelas IX MTs N 1 Surakarta.

\section{Metode Penelitian}

Lokasi penelitian difokuskan di wilayah Madrasah Tsanawiyah Negeri 1 Surakarta yang berada di Jalan MT. Haryono 24 D Surakarta. Jenis penelitian ini adalah penelitian deskriptif kualitatif. Deskriptif artinya mendeskripsikan aspek-aspek bahasa secara cermat dan teliti berdasarkan fakta-fakta kebahasaan yang sebenarnya (Sumarlam, dkk. 2010:169). Teknik pengumpulan data pada penelitian ini adalah dengan penyediaan data yang menggunakan teknik simak. Teknik simak adalah cara yang digunakann untuk memperoleh data yang dilakukan dengan menyimak penggunaan bahasa dalam tuturan (Mahsun, 2007:92). Teknik simak dalam hal ini berhubungan dengan penggunaan bahasa secara lisan. Oleh karena itu, dalam penelitian ini, yang disimak adalah penggunaan bahasa lisan oleh siswa kelas IX MTs N 1 Surakarta yang mengandung tuturan kesantunan positif. Ketika melakukan penyimakan pada percakapan dan tuturan informan, peneliti juga menggunakan teknik dasar dari teknik simak, yaitu teknik sadap.

Teknik validasi yang digunakan dalam penelitian ini yaitu teknik triangulasi. Triangulasi merupakan teknik pengecekan keabsahan data yang didasarkan pada sesuatu di luar data untuk keperluan mengecek atau sebagai pembanding terhadap data yang telah ada (Afifuddin dan Beni, 2009:155). Triangulasi yang digunakan dalam penelitian ini adalah triangulasi metode. Teknik triangulasi metode digunakan pada penelitian ini karena penelitian ini mengacu pada penelitian lain yang menggunakan metode yang berbeda. Metode analisis data yang digunakan dalam penelitian ini adalah metode padan intralingual dan padan ekstralingual. Metode padan intralingual adalah metode analisis dengan menghubungbandingkan unsur-unsur yang bersifat lingual, baik yang terdapat dalam satu bahasa maupun dalam beberapa bahasa yang berbeda, sedangkan metode padan ekstralingual adalah metode analisis dengan menghubungkan unsur-unsur bahasa yang berupa bentuk itu dengan hal yang di luar bahasa atau membandingkan hal yang diluar bahasa itu, makna dengan makna (Mahsun, 2007:118).

\section{Hasil Penelitian Dan Pembahasan}

Hasil dari analisis penelitian ini antara lain adalah menjelaskan atau mendeskripsikan tentang pola kesantunan yang digunakan oleh kalangan siswa kelas IX MTs N Surakarta 1 yang berlatar belakang kebudayaan Jawa menggunakan teori strategi kesantunan positif yang dikemukakan oleh Brown dan Levinson. Selain itu, bentuk-bentuk pergeseran kesantunan positif yang terjadi di kalangan siswa kelas IX MTs N Surakarta 1 yang berlatar belakang kebudayaan Jawa dianalisis dengan mengacu pada teori kesantunan positif Brown dan Levinson, teori Robin Lakoff (1973), dan teori mengenai skala kesantunan menurut Leech. Hasil analisis terakhir penulis menemukan faktor-faktor yang mempengaruhi pergeseran kesantunan positif di kalangan siswa kelas IX MTs N Surakarta 1 yang berlatar belakang kebudayaan Jawa.

Ada 13 pola strategi kesantunan positif yang digunakan di kalangan siswa kelas IX MTs N Surakarta 1 yang berlatar belakang kebudayaan Jawa, yaitu pola memperhatikan kesukaan, keinginan, dan kebutuhan lawan tutur. Dalam pola ini, ditemukan 5 tuturan. Pola kedua adalah membesar-besarkan perhatian, persetujuan, dan simpati kepada lawan tutur. Dalam pola ini ditemukan 1 tuturan. Selanjutnya adalah pola menggunakan penanda identitas kelompok. Dalam pola ini, ditemukan 6 tuturan. Pola mencari persetujuan dengan mengulang sebagian atau seluruh ujaran penutur (lawan tutur) ditemukan 1 tuturan; pola mengh- 
indari ketidaksetujuan dengan pura-pura setuju atau persetujuan yang semu ( $p$ sedo agreement), menipu untuk kebaikan (white lies), pemagaran opini (hedging opinion) ditemukan 5 tuturan; pola menunjukkan hal-hal yang mempunyai kesamaan melalui basa-basi (small talk) dan pranggapan (presuppasition) ditemukan 3 tuturan; pola menggunakan lelucon ditemukan 3 tuturan; pola menyatakan paham atau mengerti akan keinginan lawan tutur ditemukan 2 tuturan; pola memberikan janji ditemukan 1 tuturan; pola menunjukkan sikap keoptimisan ditemukan 2 tuturan; pola melibatkan penutur dan lawan tutur dalam aktivitas ditemu- kan 3 tuturan; pola memberikan pertanyaan atau meminta alasan ditemukan 2 tuturan; dan pola menyatakan hubungan secara timbal balik (resiprokal) ditemukan 2 tuturan. Jadi, keseluruhan ada 36 tuturan yang menjadi data yang telah dianalisis dalam penelitian ini.

Pola-pola yang dijabarkan di atas memiliki bentuk-bentuk tuturan yang berbeda antara satu pola dengan pola yang lain. Persentase jumlah data dari pemakaian masing-masing pola kesantunan positif di kalangan siswa MTs N 1 Surakarta yang berlatar belakang kebudayaan Jawa ditunjukkan pada gambar di bawah ini.

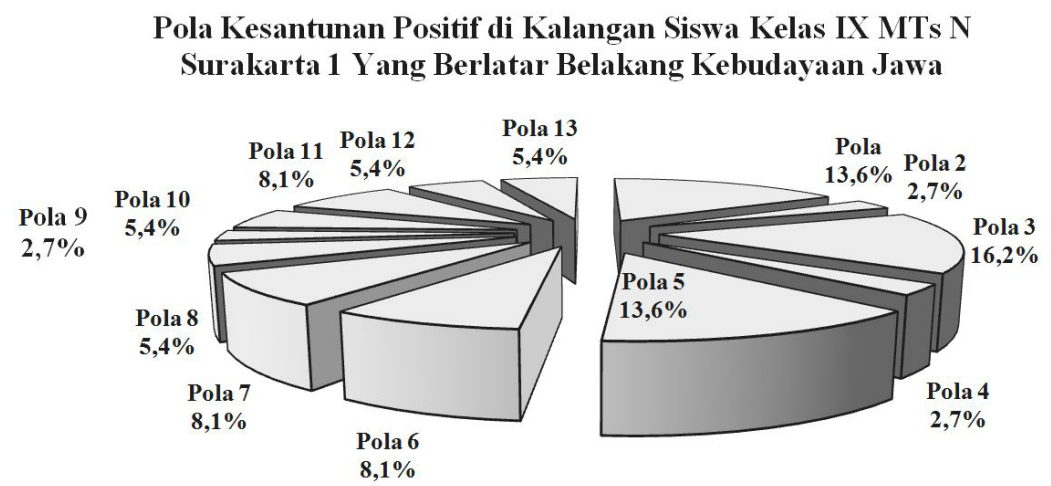

Gambar 1. Pola Kesantunan Positif di Kalangan Siswa Kelas IX MTs N Surakarta 1 yang Berlatar Belakang Kebudayaan Jawa

Hasil dan temuan dari bentuk-bentuk tuturan yang mengalami pergesaran kesantunan positif di atas berhubungan dengan ancaman muka serta skala kesantunan yang menjadi pengukur tingkat kesantunan, yaitu antara lain bentuk pergeseran dari tindak tutur ekspresif Pn yang tidak menghindarkan ancaman wajah terhadap Mt, dari tindak tutur ekspresif dengan bentuk interogatif yang mengancam muka positif, dari tindak tutur direktif yang mengancam muka positif, dari tindak tutur ekspresif dengan bentuk pernyataan, dari tindak tutur imperatif yang mengancam muka positif, serta dari tindak tutur ekspresif menjadi direktif. Berikut adalah pembahasan data dari bentuk dari tindak tutur direktif yang tidak memperhatikan skala kesantunan untung-rugi dan pilihan sehingga mengalami pergeseran kesantunan positif.
$(2)$
Dinar: "Tak garapke, anggere ngko aku dijajakke lho yoo."
(Saya kerjakan, tapi nanti aku di traktir ya)
Lisdyanto : "Gah, rasido." (Tidak jadi)

Konteks: Pn ingin memberi bantuan kepada Mt dengan imbalan Mt mentraktir Pn. Pn akan mengerjakan tugas Mt, kalau Mt mau mentraktir Pn.

Bentuk pergeseran kesantunan positif yang terjadi dalam tuturan (2), yaitu "Tak garapke, anggere ngko aku dijajakke lho yoo". Apabila dilihat dengan menggunakan skala untung-rugi dan pilihan, semula Pn menawarkan kebutuhan timbal balik 
dengan Mt, tetapi kemudian menjadi bentuk imperatif. Pilihan yang ditawarkan Pn kepada Mt mengandung makna yang sama-sama mengancam muka Pn dan Mt. Bentuk pergeseran kesantunan positif dari beberapa pola kesantunan yang digunakan secara rinci akan dijelaskan melalui tabel 2 di bawah ini.

Tabel 1. Klasifikasi bentuk pergeseran kesantunan positif di kalangan siswa kelas IX MTs N 1 Surakarta yang berlatar belakang kebudayaan Jawa

\begin{tabular}{|c|c|c|c|}
\hline Bentuk Pergeseran & $\begin{array}{l}\text { Nomor } \\
\text { Data }\end{array}$ & Bentuk Tuturan & Strategi yang Digunakan \\
\hline $\begin{array}{l}\text { TT Ekspresif Terha- } \\
\text { dap Ancaman Wajah. }\end{array}$ & $\begin{array}{l}5,6, \text { dan } \\
21\end{array}$ & $\begin{array}{l}\text { Interogatif } \\
\text { (Memuji) Ekspre- } \\
\text { sif }\end{array}$ & $\begin{array}{l}\text { P1 } \\
\text { (Memperhatikan kesukaan, keinginan, } \\
\text { dan kebutuhan lawan tutur) P7 } \\
\text { (Menggunakan Lelucon) }\end{array}$ \\
\hline $\begin{array}{l}\text { TT Ekspresif dengan } \\
\text { Bentuk Interogatif } \\
\text { yang Mengancam } \\
\text { Wajah Positif }\end{array}$ & $\begin{array}{l}3,4,19 \\
\text { dan } 26\end{array}$ & Ekspresif & $\begin{array}{l}\text { P2 } \\
\text { (Membesar-besarkan perhatian, per- } \\
\text { setujuan, dan simpati kepada lawan tu- } \\
\text { tur), P5 } \\
\text { (Menghindari ketidaksetujuan dengan } \\
\text { pura-pura setuju, persetujuan yang } \\
\text { semu (Psedo agreement), menipu un- } \\
\text { tuk kebaikan(white lies), pemagaran } \\
\text { opini(hedging opinion) }\end{array}$ \\
\hline $\begin{array}{l}\text { TT Direktif Terhadap } \\
\text { Ancaman Wajah }\end{array}$ & 14 & Direktif & $\begin{array}{l}\text { P3 } \\
\text { (Menggunakan penanda indentitas } \\
\text { kelompok seperti sapaan, jargon, dan } \\
\text { slang) }\end{array}$ \\
\hline $\begin{array}{l}\text { TT Imperatif Terha- } \\
\text { dap Ancaman Wajah }\end{array}$ & 1 & Imperatif & $\begin{array}{l}\text { P11 } \\
\text { (Melibatkan penutur dan lawan tutur } \\
\text { dalam aktivitas) }\end{array}$ \\
\hline $\begin{array}{l}\text { TT Ekspresif Menja- } \\
\text { di Bentuk Direktif. }\end{array}$ & 11 & Ekspresif & $\begin{array}{l}\text { P } 12 \\
\text { (Meminta alasan) }\end{array}$ \\
\hline $\begin{array}{l}\text { TT Direktif dengan } \\
\text { Skala Kesantunan. }\end{array}$ & 8 dan 13 & Direktif & $\begin{array}{l}\text { P } 13 \\
\text { (Menyatakan (Resiprokal) hubungan } \\
\text { secara timbale balik) }\end{array}$ \\
\hline
\end{tabular}

Dari klasifikasi di atas, ditemukan 6 bentuk pergeseran kesantunan positif dari data yang sudah dianalisisi menggunakan ketiga belas pola kesantunan positif yang digunakan di kalangan siswa kelas IX MTs Negeri 1 Surakarta. Pola kesantunan yang mengalami pergeseran, antara lain dengan menggunakan strategi memperhatikan kesukaan, keinginan, dan kebutuhan lawan tutur, strategi menggunakan lelucon, strategi membesar-besarkan perhatian, persetujuan, dan simpati kepada lawan tutur, strategi menghindari ketidaksetujuan dengan pura-pura setuju, persetujuan yang semu (Pseudo agreement), menipu untuk kebaikan (white lies), pemagaran opin$\mathrm{i}$ (hedging opinion), strategi menggunakan penanda indentitas kelompok seperti sapaan, jargon, dan slang), strategi melibatkan penutur dan lawan tutur dalam aktivitas, dan strategi meminta alasandan strategi menyatakan hubungan secara timbal balik (Resiprokal).

Sementara itu, faktor yang mempengaruhi pergeseran kesantunan positif di kalangan siswa kelas IX MTs N Surakarta 1 yang berlatar belakang kebudayaan Jawa dilihat dari data yang telah dianalisis men- 
genai pola kesantunan dan bentuk-bentuk tuturan yang mengalami pergesaran kesantunan positif di kalangan siswa kelas IX MTs N Surakarta 1 yang berlatar belakang kebudayaan Jawa mencakup enam faktor. Pertama adalah jarak sosial serta hubungan antara penutur, lawan tutur dan mitra tutur. faktor ini tersebut sangat mempengaruhi tingkat kesantunan positif di kalangan siswa MTs N1 Surakarta. Kedua adalah konteks. Konteks mempengaruhi maksud tuturan. Artinya, konteks berhubungan dengan situasi yang berhubungan dengan suatu kejadian. Lingkungan non linguistik ujaran merupakan alat untuk memahami makna dan maksud suatu ujaran. Ketiga adalah keinginan untuk memuji yang berlebihan (Nglulu). Dalam istilah Jawa, kata nglulu atau memuji yang berlebihan serta memperhatikan kebutuhan mitra tutur dengan berlebihan ini menjadi penyebab pergeseran kesantunan positif yang terlalu mengancam muka dari penuturnya sendiri. Keempat adalah sengaja meminta alasan. Pada faktor ini, penutur tidak serta merta menyalahkan mitra tutur. Ujaran yang digunakan seringkali berupa kalimat interogatif yang kadang-kadang mengalami pergeseran kesantunan yang secara tidak langsung mengancam muka si mitra tutur. Faktor kelima adalah tidak ingin dirugikan. Pada analisi data, siswa seringkali menggunakan pola (resiprokal) yang menyatakan hubungan secara timbal balik. Ujaran penutur terhadap mitra tutur sering tidak memperhatikan skala pengukur kesantunan berbahasa yang diungkapkan Leec. Hal ini karena diantaranya ada skala kerugian dan keuntungan serta skala pilihan. Beberapa skala itu sering dihiraukan oleh penutur, lawan tutur, maupun mitra tutur. Faktor keenam adalah penolakan terhadap sesuatu. Faktor ini sering menjadi penyebab pergeseran kesantunan positif bagi penutur yang menggunakan strategi atau pola menghindari ketidaksetujuan dengan pura-pura setuju, persetujuan yang semu (psedo agreement), menipu untuk kebaikan (white lies), atau pemagaran opini (hedging opinion). Hal ini karena penutur atau mitra tutur biasa memakai jawaban interogatif (jawa- ban yang berupa pertanyan). Selain itu, penolakan ini juga dapat berupa pernyataan.

\section{Simpulan}

Berdasarkan deskripsi hasil dan pembahasan dalam analisis di atas, dapat disimpulkan bahwa terdapat 13 pola strategi kesantunan positif yang digunakan di kalangan siswa kelas IX MTs N Surakarta 1 yang berlatar belakang kebudayaan Jawa. Ketiga belas pola tersebut adalah pola memperhatikan kesukaan, keinginan, dan kebutuhan lawan tutur; pola membesar-besarkan perhatian, persetujuan, dan simpati kepada lawan tutur; pola menggunakan penanda identitas kelompok; pola mencari persetujuan dengan mengulang sebagian atau seluruh ujaran penutur (lawan tutur); pola menghindari ketidaksetujuan dengan pura-pura setuju atau persetujuan yang semu (psedo agreement), menipu untuk kebaikan (white lies), pemagaran opini (hedging opinion); pola menunjukkan hal-hal yang mempunyai kesamaan melalui basa-basi (small talk) dan pranggapan (presuppasition; pola menggunakan lelucon; pola menyatakan paham atau mengerti akan keinginan lawan tutur; pola memberikan janji; pola menunjukkan sikap keoptimisan; pola melibatkan penutur dan lawan tutur dalam aktivitas; pola memberikan pertanyaan atau meminta alasan; dan pola menyatakan hubungan secara timbal balik (resiprokal).

Sementara itu, bentuk-bentuk tuturan yang mengalami pergesaran kesantunan positif, antara lain dari tuturan ekspresif terhadap ancaman wajah, dari tuturan ekspresif dengan bentuk interogatif yang mengancam wajah positif, dari tuturan direktif terhadap ancaman wajah, dari tuturan imperatif terhadap ancaman wajah, dari tuturan ekspresif menjadi bentuk direktif, dari tuturan direktif dengan skala kesantunan.

Ada 6 faktor yang mempengaruhi pergeseran kesantunan positif di kalangan sisiwa kelas IX MTs N 1 Surakarta yang berlatar belakang kebudayaan Jawa. Keenam faktor tersebut adalah (1) jarak sosial, (2) konteks, (3) keinginan untuk memuji 
yang berlebihan (nglulu), (4) sengaja meminta alasan, (5) tidak ingin dirugikan, dan
(6) penolakan terhadap sesuatu.

\section{Daftar Pustaka}

Afifudin dan Beni Ahmad Saebani. 2009. Metodologi Penelitian Kualitatif. Bandung: CV Pustaka Setia.

Brown, P. and S. C. Levinson. 1987. Politeness: Some universals in Language usage. Cambridge: Cambridge University Press.

Chaer, Abdul. 2010. Kesantunan Berbahasa. Jakarta: Rineka Cipta.

Chaer, Abdul. 2007. Kajian Bahasa Struktur Internal, Pemakaian dan Pemelajaran. Jakarta: Rineka Cipta.

CummingS,Louise. 2007. Pragmatik Sebuah Prespektif Multidisipliner. Yogyakarta: Pustaka Pelajar.

Rustono. 1999. Pokok-Pokok Pragmatik. Semarang: IKIP Semarang Press.

Tarigan, H.G. 1968. Pengajaran Pragmatik. Bandung: Angkasa.

Sumarlam, dkk. 2010. Teori dan Praktik Analisis Wacana. Solo: Putra Cakra Surakarta.

Syamsuddin dan Vismaia S. Darmaianti. 2009. Metode Penelitian Pendidikan Bahasa. Bandung: PT.Remaja Rosdakarya.

Yule, George. 2008. Pragmatik. Yogyakarta: Pustaka Pelajar.

Parera.1980. Teori Semantik. Jakarta: PT Raja Grafindo Persada.

Pranowo. 2008. "Kesantunan Berbahasa Indonesia Sebagai Pembentuk Kepribadian Bangsa" dalam Jurnal Gatra No.34 Th,xxiv/Januari 2008. PBSID FKIP Universitas Sanata Dharma Yogyakarta.

Prayitno, Harun Joko. 2011. Kesantunan Sosiopragmatik: Studi Pemakaian Tindak Direktif di Kalangan Andik SD Berbudaya Jawa. Surakarta: Muhammadiyah University Press.

Prayitno, Harun Joko. 2012. "Realisasi Tindak Tutur Direktif Dalam Pembelajaran Pragmatik: Berdaya, Berorientasi, dan Berstrategi Kesantunan Positif" dalam Pidato Pengukuhan Guru Besar Bidang Ilmu Pragmatik dan Pengajarannya. Universitas Muhammadiyah Surakarta.

Grice, H.P. 1975. Logic and Conversation. In Peter Cole and J.L. Morgan (eds.) Syntax and Semantics, Vol. 3: Speech Acts, New York: Academic Press. pp. 41-58.

Lakoff, R. T. 1990. Talking Power: The Politics of Language in Our Lives. Glasgow: Harper Collins.

Mahsun. 2005. Metode Penelitian Bahasa Tahapan strategi, metode, dan tekniknya. Jakarta: PT Raja Grafindo Persada.

Maryadi, dkk. 2011. Pedoman Penulisan Skripsi FKIP. Surakarta: BP-FKIP Universitas Muhammadiyah Surakarta.

Moleong, Lexy. 2007. Metodologi Penelitian Kualitatif. Bandung: PT Remaja Rosdakarya.

Muslich, Masnur. 2007. Kesantunan Berbahasa: Sebuah Kajian Sosiolinguistik.

Wijana, I Dewa Putu. 1996. Dasar-Dasar Pragmatik. Yogyakarta: Andi Offset 